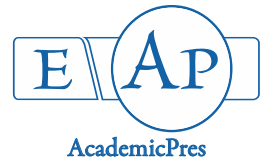

\title{
Ultrasonic Assisted Seed Priming to Alleviate Aging Damages to Milk Thistle (Silybum marianum) Seeds
}

\section{Seyed Amir MOOSAVI ${ }^{1 *}$, Seyed Ataollah SIADAT ${ }^{2}$, Adel POSHTDAR ${ }^{3}$, Fatemeh DIREKVAND ${ }^{4}$}

\author{
${ }^{I}$ Khuzestan University of Agricultural Sciences and Natural Resources, Faculty of Agriculture, Assistant Professor of Department of Plant \\ Production and Genetics, Mollasani, Iran; amirmoosavi@ramin.ac.ir;amir.msa@gmail.com ("correspondingauthor) \\ ${ }^{2}$ Khuzestan University of Agricultural Sciences and Natural Resources, Faculty of Agriculture, Professor of Department of Plant Production and \\ Genetics, Mollasani, Iran; Seyedatasiadat@yahoo.com \\ ${ }^{3}$ Khuzestan University of Agricultural Sciences and Natural Resources, Faculty of Agriculture, Researcher of Department of Plant Production \\ and Genetics, Mollasani, Iran; adelposhtdar@gmail.com \\ ${ }^{4}$ Khuzestan University of Agricultural Sciences and Natural Resources, Researcher of Central Laboratory, Mollasani, Iran; \\ direkvand.fatemeh@yahoo.com
}

\begin{abstract}
Milk thistle is a medicinal plant with high pharmaceutical properties to help relief of liver diseases. In this study, the effects of ultrasonic assisted seeds priming (20, 40, 80 and $160 \mathrm{~s}$ ) with a frequency of $24 \mathrm{kHz}$ and Power of $400 \mathrm{~W}$ was investigated on seed enhancement of aged seeds of Milk thistle. Results of the study, showed that as the aging damages increased, the longer sonication results in the better germination. Root growth was significantly improved using ultrasonic energy. Seeds aged for 24 hours, were exposed to ultrasonic produced for 20 seconds exhibited root length of $10.39 \mathrm{~cm}$ which was $5.48 \mathrm{~cm}$ with no ultrasonic treatment with the same aging duration. The maximum malondialdehyde activity was observed at the 96 -hour aging treatment $(87.83 \mathrm{nmol} / \mathrm{grFW})$ while the lowest activity was observed at no aged and 24-hour aged seeds $(7.28 \mathrm{nmol} / \mathrm{grFW})$. It is suggested that there is a negative correlation between seedling vigor and MAD activity. It was revealed that fatty acid composition of Silybum marianum seed oil is highly influenced by the aging treatment. The variations of unsaturated fatty acids significantly increased in aged seeds. Our results showed that under accelerated aging conditions, ultrasonic assisted seed priming could not provide satisfactory enhancement to seed germination while no aged seeds germination was significantly improved using ultrasonic assisted seed priming.
\end{abstract}

Keywords: Accelerated aging, fatty acid, malondialdehyde, ultrasonic

\section{Introduction}

Milk thistle (Silybum marianum L.) is belong to daisy family (Asreraceae) which grows as winter annual or biennial plant and primarily propagated by its seeds (Adzet et al., 1993). Milk thistle spreads rapidly and is categorized as a weed in some parts of the world (Gresta et al., 2007). This plant has medicinal properties and has been used for many years as a natural remedy to cure liver diseases (Henning et al., 2014). Seeds are oval shape achenes with color ranging from black to brown (Andrzejewska and Sadowska, 2008). Seed extract of milk thistle contains Isosilibinin which is the most potent inhibitor in human lives microsomes (Albassam et al., 2017). Silybin is valuable bioactive compound with great antioxidant and anticancerogenic properties, derived from milk thistle seeds
(Flora et al., 1998; Çelik and Gürü, 2015; Li et al., 2018).

Although Milk thistle has great pharmaceutical properties but it also can easily turns to a weed to it capability to produce large number of seeds and their longevity in soil (Karkanis et al., 2011).

Among all different environmental stress which affects seed vigor and viability, seed ageing is a common stress especially in soil seed bank or seed storage rooms. Seed ageing decreases quality of seedling growth and germination traits in many of the plants. Different physiological processes are active during ageing. Changes in anti-oxidative activity, reverse mobilization and embryo weakening are severe effects of seed ageing.

Lipid peroxidation may be the main key factor of decreasing seed quality by seed ageing. It is initiate with generation of free oxygen radicals either by autoxidation of enzymatically by oxidative enzymes (Gille and Joenje, 1991; 
276

Larson, 1997; McDonald, 1999). Seed priming is known as effective seed treatment to improve germination and seedling growth in many crops species. This technique is mainly alters the imbibition phase of seed germination in such a way that the most of germination process including DNA, RNA repairs, protein and enzymes synthesis will progress to provide satisfactory condition for completion of seed germination but meanwhile every process keep hold right before radicle emergence by the restriction of water uptake. Thus germination process remains incomplete.

During seed priming, seeds allowed to imbibe for the certain amount of time with targeted priming media that could be macro and micro nutrients, growth regulators (Gibberllic acid, Cytokinin, Auxin); salts ( $\mathrm{Kno}_{3}, \mathrm{NaCl}$ ); Osmotica (Polyethylen glycol, Manitol) or only distilled water known as hydropriming. The time of seed priming is very crucial factor to have a successful seed treatment.

\section{Ultrasound and why ultrasonic}

Ultrasound is defined by the American National Standards Institute as "sound at frequencies greater than 20 $\mathrm{kHz}$." It is basically, a type of energy which is transferred inform of waves across air, water, etc. In case of liquid, passing ultrasound waves with high-intensity they are forming microscopic tiny voids which become bubbles containing water vapor or gas. These small bubbles grow gradually during extension phase till they imploded. This phenomenon is called cavitation. Cavitation is responsible for most of ultrasonic effects on target material. It provides high pressure and temperature at the same time at the impact point which the bubbles imploded.

The objective of this study was to examine the effects of ultrasonic assisted seed priming on germination improvement of aged seeds and evaluation the alterations of aged related enzyme activities. We are trying to investigate whether the ultrasonic assisted seed priming has a positive effect on repairing the damages to germination quality as the results of seed aging.

\section{Materials and Methods}

\section{Seed materials}

The Milk thistle seeds were collected in dry state form local untreated fields of Khuzestan University of Agricultural Sciences and Natural Resources, Mollasani, Iran $\left(31^{\circ} 35^{\prime} \mathrm{N}, 48^{\circ} 53^{\prime} \mathrm{E}\right)$ in growing season of 2017 . Seeds were then cleaned from the white pappus and proceed to seed technology laboratory of department of plat production and genetics.

\section{Accelerated ageing}

For the accelerated aging test, $200 \mathrm{~mL}$ of distilled water was added to each plastic box $\left(20^{*} 15^{*} 10 \mathrm{~cm}\right)$ and 200 seeds were placed on a wired mesh tray $\left(19^{*} 14^{*} 10 \mathrm{~cm}\right)$ inside the box. To avoid direct content of seed with water, they were placed at the middle part of tray. Seed were aged at $40{ }^{\circ} \mathrm{C}$ and $99 \%$ humidity for $24,48,72$ and 96 h using one box is used for each aging/time combination (Demir and Mavi, 2008; Souza et al., 2017). Seeds were subjected to disinfection treatment before standard germination test using $3 \%$ solution of $\mathrm{NaOCl}$ (Sauer, 1986).

\section{Ultrasonic assisted seed priming treatment}

Ultrasonification was conducted using Hielscher UP 400 ultrasonic instrument. This devise is powerful ultrasonic instrument capable of provide $400 \mathrm{~W}$ energy at $24 \mathrm{kHz}$ frequency. Seed were immersed into the distilled water as hydro priming media and subjected to different ultrasonifications durations including $(20,40,80$ and 160 seconds).

After ultrasonic assisted seed priming, all treatments were transferred to Petri dishes with $9 \mathrm{~cm}$ diameter containing two layers of Watmant filter paper. Number of 25 seeds per petri dish were moistened with $4 \mathrm{ml}$ distilled water and subjected to standards germination test $\left(20^{\circ} \mathrm{C}\right)$ based on the ISTA rules for seed germination. Upon completion of ageing treatments, aged and no aged seeds were subjected to standard germination test using ISTA rules for seed germination of Silybum marianum (ISTA, 2013).

The germinated seeds were counted each day for 7 days. The shoot and root length were measured on the seventh day after cultured seeds in Petri dishes and 10 seedlings were measured from each Petri dish of four replications. Seed were considered as germinated when sprouted radicle was 2 mm long. The Final Germination Percentage (FGP), Mean germination time (MGT), Germination Rate (Gr) were calculated using following formulas:

FGP $=$ Final no. of seeds germinated in seed lot $\times 100$ (Scott et al., 1984)

$M G T=\sum f \cdot x / \sum f G r=1 / M G T$

Where: $\mathrm{f}=$ Seeds germinated on day (Orchard, 1977)

The seedling vigor index was measured using following formulae (Liu et al., 2016):

Vigor $==$ FGP. $S_{(\mathrm{Cm})}$

Where: $S$ is length of seedling (root+shoot)

\section{Enzyme activity assay and membrane integrity test}

Malondialdehyde activity was measured using colorimetric method fully described by (Heath and Packer, 1968; Stewart and Bewley, 1980). Treated seeds were homogenized in $5 \mathrm{ml}$ of distilled $\mathrm{H}_{2} \mathrm{O}$ upon completion of imbibition phase. An equal volume of $0.5 \% 2$-thiobarbituric acid (TBA) in $20 \%$ trichloroacetic acid solution was added and the sample was incubated at $95 \mathrm{C}$ for $30 \mathrm{~min}$. The reaction was stopped by putting the reaction tubes in an ice bucket. The samples then were centrifuged at $10,000 \mathrm{~g}$ for $30 \mathrm{~min}$. The supernatant was removed, A was read at 532 $\mathrm{nm}$, and the value for nonspecific absorption at $600 \mathrm{~nm}$ was read and subtracted from this. The amount of the malondialdehyde present was calculated from the extinction coefficient of $155 \mathrm{mM}^{-1} \mathrm{~cm}^{-1}$ (Kwon et al., 1965). To investigate the interaction effect of accelerated aging and ultrasonic seed priming on the membrane integrity of treated seeds, the residual liquid after sonifications was tested for electrical conductivity and data were recorded for each individual treatment.

\section{Gas chromatography (FAME detection)}

The analysis of fatty acid methyl esters (FAMEs) were performed using Agilent Gas chromatography by HP-FFAP column. The standards were dissolved in hexane at a 0.01 to 
$0.1 \%(\mathrm{w} / \mathrm{v})$ concentration. Weight of $100 \mathrm{mg}$ from each treated samples were putted in reaction vial and dissolved in $10 \mathrm{Ml}$ hexane. $100 \mu \mathrm{l} 2 \mathrm{~N}$ potassium hydroxide were added to methanol, mixed with reaction vial content. All mixture vials were vortexed for 30 Seconds, Centrifuged and clear supernatant was ready to inject into Agilent gas chromatography station. Agilent GC equipped with FID detection was programed for Automatic split injection program (David and Vickers, 2005). Data were analyzed using Microsoft Excel and Minitab software (Levine et al., 2001).

\section{Results and Discussion}

\section{Germination indices}

Accelerated aging treatment resulted in reduction of germination indices of Silybum marianum. Our results revealed that the root growth is $41 \%$ lower in the accelerated aged seeds for 24 hour compared to control (Fig. 1). However, application of ultrasonic assisted seed priming for the durations of 40 seconds, not only alleviate root growth damage by accelerated aging treatment ( 24 hour) but also produced longer roots (Table 1). Shoot length was only significantly influence by the accelerated aging durations of 96 hour. At this aging treatment, ultrasonic seed priming did not exhibited any improvement of shoot growth compared to control. Ultrasonic assisted seed priming for the durations of 80 seconds successfully improved shoot growth of no aged seeds about $79 \%$ compared to no primed seeds (Table 1). Germination percentage of no aged seeds was significantly reduced as the time of ultrasonic seed priming increased. Also, this treatment did not produce any satisfactory results of seed germination for the aged seeds except at 160 seconds (Table 1).

Our results showed that, at the sever aged treatments, ultrasonic assisted seed priming, increase the mean germination time of treated seeds and as the results germination rate of treated seeds reduced (Table 1, Fig. 1). Seedling vigour was negatively influenced by the accelerated aging at no ultrasonic assisted seed treatment and it decreased about $80 \%$ of control seeds by the aging for the durations of 96 hour. Although applications of ultrasonic assisted seed priming could improve seedling vigour of aged seeds but it did not exhibited the consistent pattern (Table 1). It was suggested that the free radical scavenging and lipid peroxidation are the main causes of accelerated aging damages to germination quality of sunflower seeds (Bailly $e t$ al., 1998). It was reported that the accelerated aging caused mitochondrial damages and influence the energy demanding process required for seed germination (Benamar et al., 2003). Our results showed that the accelerated aging caused significant reduction of seed germination quality and this might be due to membrane integrity losses beside of lipid peroxidation. As the durations of accelerated aging increased, the seed vigour index was drastically decreased. Similar results were reported for chickpea (Kapoor et al., 2010) and cotton seeds (Goel et al., 2003).

It has been reported that accelerated aging resulted in

Table 1. Mean comparison of interaction effects (Aging durations ${ }^{*}$ Ultrasonic Assisted Sp)

\begin{tabular}{|c|c|c|c|c|c|c|c|}
\hline $\begin{array}{l}\text { Ageing } \\
\text { (hour) }\end{array}$ & $\begin{array}{l}\text { Ultrasonic } \\
\text { (seconds) }\end{array}$ & $\operatorname{Root}(\mathrm{cm})$ & Shoot $(\mathrm{cm})$ & FGP $(\%)$ & MGT & $\mathrm{Gr}$ & Vigor \\
\hline \multirow{5}{*}{ No Aged } & 0 & $9.34 \pm 0.59$ & $1.53 \pm 0.1$ & $98.67 \pm 2.31$ & $1.4 \pm 0.11$ & $0.72 \pm 0.06$ & $1074.09 \pm 84.25$ \\
\hline & 20 & $10.33 \pm 0.17$ & $2.62 \pm 0.18$ & $86 \pm 6$ & $1.63 \pm 0.14$ & $0.62 \pm 0.05$ & $1113.97 \pm 77.96$ \\
\hline & 40 & $7.83 \pm 1.09$ & $2.29 \pm 0.18$ & $88 \pm 4$ & $2.21 \pm 0.34$ & $0.46 \pm 0.07$ & $538.27 \pm 18.32$ \\
\hline & 80 & $9.75 \pm 1.25$ & $2.74 \pm 0.13$ & $90.67 \pm 10.07$ & $1.14 \pm 0.13$ & $0.89 \pm 0.1$ & $1137.93 \pm 212.64$ \\
\hline & 160 & $9.92 \pm 0.42$ & $2.58 \pm 0.37$ & $54 \pm 2$ & $1.53 \pm 0.05$ & $0.66 \pm 0.02$ & $674.92 \pm 36.81$ \\
\hline \multirow{5}{*}{24} & 0 & $5.48 \pm 0.18$ & $1.69 \pm 0.22$ & $97.33 \pm 2.31$ & $1.38 \pm 0.06$ & $0.72 \pm 0.03$ & $697.47 \pm 12.6$ \\
\hline & 20 & $7.94 \pm 1.25$ & $2.64 \pm 0.37$ & $98 \pm 2$ & $1.57 \pm 0.11$ & $0.64 \pm 0.05$ & $1037.87 \pm 161.34$ \\
\hline & 40 & $10.39 \pm 0.38$ & $3.46 \pm 0.44$ & $65.33 \pm 2.31$ & $1.39 \pm 0.04$ & $0.72 \pm 0.02$ & $905.64 \pm 82.93$ \\
\hline & 80 & $10.56 \pm 0.48$ & $2.47 \pm 0.28$ & $64 \pm 4$ & $1.06 \pm 0$ & $0.94 \pm 0$ & $834.09 \pm 73.25$ \\
\hline & 160 & $7.83 \pm 0.33$ & $2.89 \pm 0.25$ & $65.33 \pm 10.07$ & $1.85 \pm 0.09$ & $0.54 \pm 0.02$ & $697.33 \pm 78.46$ \\
\hline \multirow{5}{*}{48} & 0 & $2.92 \pm 0.29$ & $1.52 \pm 0.13$ & $96 \pm 0$ & $1.58 \pm 0.13$ & $0.63 \pm 0.05$ & $426.67 \pm 35.39$ \\
\hline & 20 & $2.89 \pm 0.59$ & $2.28 \pm 0.2$ & $64 \pm 6.93$ & $1.74 \pm 0.19$ & $0.58 \pm 0.06$ & $327.33 \pm 22.8$ \\
\hline & 40 & $4.94 \pm 0.42$ & $2.07 \pm 0.09$ & $84.67 \pm 3.06$ & $1.35 \pm 0.48$ & $0.8 \pm 0.24$ & $623.58 \pm 108.84$ \\
\hline & 80 & $3.38 \pm 0.28$ & $1.58 \pm 0.52$ & $42 \pm 5.29$ & $2.73 \pm 0.07$ & $0.37 \pm 0.01$ & $205.93 \pm 11.45$ \\
\hline & 160 & $4.58 \pm 0.42$ & $2.58 \pm 0.42$ & $78 \pm 2$ & $2.4 \pm 0.11$ & $0.42 \pm 0.02$ & $559.56 \pm 74.13$ \\
\hline \multirow{5}{*}{72} & 0 & $2.33 \pm 0.19$ & $1.43 \pm 0.25$ & $96 \pm 4$ & $2.03 \pm 0.08$ & $0.49 \pm 0.02$ & $361.56 \pm 15.98$ \\
\hline & 20 & $5.58 \pm 0.92$ & $2.5 \pm 0.5$ & $82 \pm 2$ & $1.39 \pm 0.08$ & $0.72 \pm 0.04$ & $661.94 \pm 53.26$ \\
\hline & 40 & $3.23 \pm 0.3$ & $2.44 \pm 0.16$ & $56 \pm 4$ & $2.03 \pm 0.2$ & $0.5 \pm 0.05$ & $280.8 \pm 30.71$ \\
\hline & 80 & $4.08 \pm 0.42$ & $1.71 \pm 0.2$ & $56 \pm 4$ & $2.43 \pm 0.39$ & $0.42 \pm 0.07$ & $323.16 \pm 10.09$ \\
\hline & 160 & $5.08 \pm 0.08$ & $2.36 \pm 0.37$ & $76 \pm 6.93$ & $2.3 \pm 0.25$ & $0.44 \pm 0.05$ & $564.93 \pm 50.03$ \\
\hline \multirow{5}{*}{96} & 0 & $2.03 \pm 0.03$ & $1.1 \pm 0.09$ & $66 \pm 2$ & $2.52 \pm 0.33$ & $0.4 \pm 0.05$ & $206.89 \pm 11.24$ \\
\hline & 20 & $1.5 \pm 0.29$ & $0.26 \pm 0.05$ & $14 \pm 2$ & $5.36 \pm 0.38$ & $0.19 \pm 0.01$ & $28.84 \pm 1.55$ \\
\hline & 40 & $0.52 \pm 0.12$ & $0.12 \pm 0.02$ & $8.67 \pm 1.15$ & $5.1 \pm 0.66$ & $0.2 \pm 0.03$ & $5.6 \pm 1.41$ \\
\hline & 80 & $0.27 \pm 0$ & $0.02 \pm 0.01$ & $8.67 \pm 1.15$ & $5.83 \pm 0.29$ & $0.17 \pm 0.01$ & $2.55 \pm 1.15$ \\
\hline & 160 & $1.46 \pm 0.17$ & $0.48 \pm 0.08$ & $13.33 \pm 2.31$ & $5.44 \pm 0.51$ & $0.19 \pm 0.02$ & $25.02 \pm 4.89$ \\
\hline
\end{tabular}



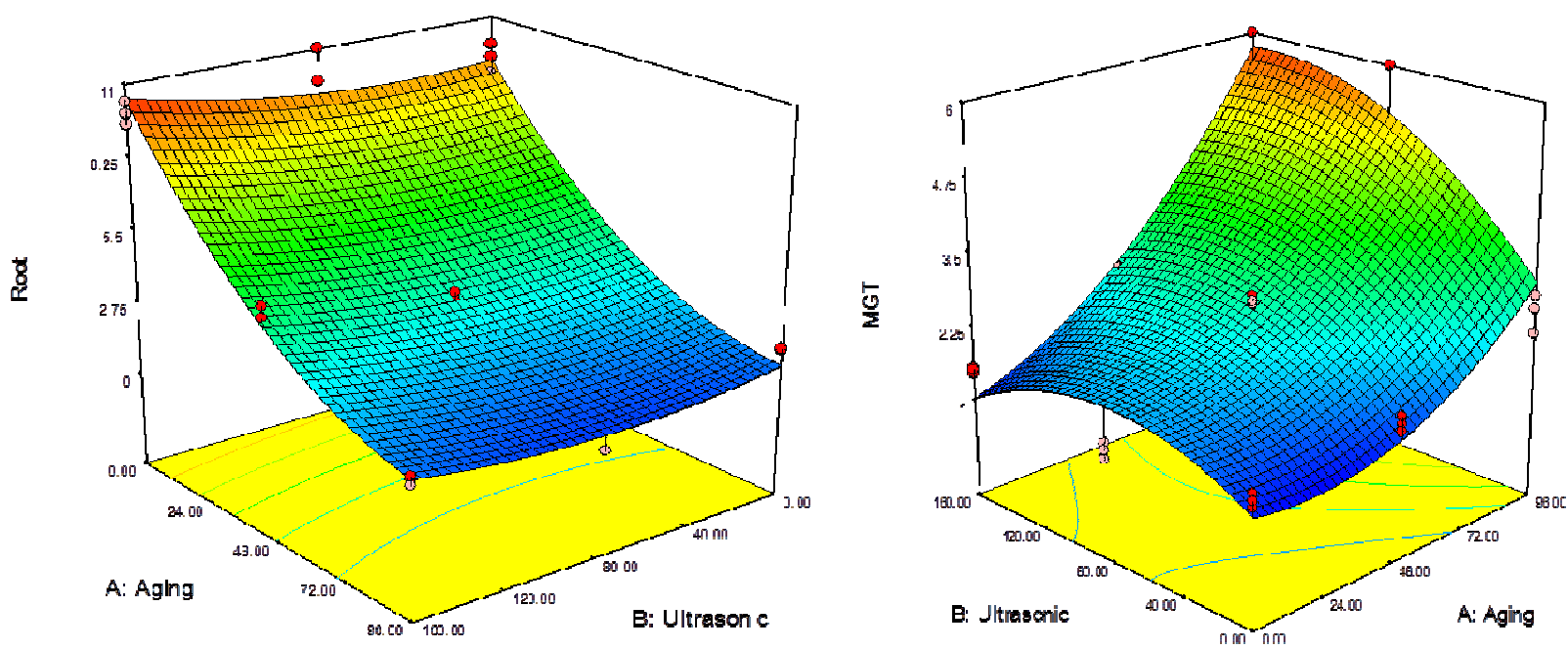

Fig. 1. Responses of root length and mean germination time to interaction effects of ultrasonic and aging treatments

malfunction of Milk thistle seed antioxidants activity which led to damages of seed germination parameters and seedling growth (Parmoon et al., 2013). Treatment of wild rice with ultrasonic waves at $70 \mathrm{kc} / \mathrm{s}$ for $10 \mathrm{~min}$ increased seed germionation while increasing either the intensity or duration of treatment declined seed germination (Halstead and Vicario, 1969). It has been reported that seed treatment with ultrasonic waves could significantly alleviate seed dormancy of Artiplex lentiformis and seed germination percentage was enhanced form $40 \%$ in control treatment to $70 \%$ by using $5 \mathrm{~min}$ ultrasonification (Sharififar et al., 2015). Ultrasonic treatment of barley seed increased 1.042 fold relative to the control treatment and mean germination time reduced $45 \%$ of the control treatment (Yaldagard et al., 2008).

\section{Enzyme activity and electrical conductivity test}

Our results revealed that the MAD is a good indicator of aging condition for Silybum marianum seeds. The lowest MAD activity was observed at no aged seeds. The maximum MAD activity was obtained at the 96 hour aging treatment $(87.83 \mathrm{nmol} / \mathrm{grFW})$ while the lowest activity was observed at no aged and 24 hour aged seeds $(7.28 \mathrm{nmol} / \mathrm{grFW}$ ) (Fig. 2 ). It is suggested that there is negative correlation between seedling vigor and MAD activity. Application of Ultrasonic assisted seed priming, lowered the MAD activity especially at 72 and 96 hours of aged treatment. Malondialdehyde is a chemical output of the peroxidation of unsaturated fatty acids (Stewart and Bewley, 1980). Seed oil of Silybum marianum is mainly consisted of unsaturated fatty acids, such as Octadecenoic which is dramatically decreased during aging treatments.

Ultrasonic assisted seed priming increased electrolyte leakage from seeds. In the no aged treatment, application of ultrasonic for 80 seconds resulted more than of two times greater electrolyte leaching $(74.1 \mathrm{mmohs} / \mathrm{cm})$ from seeds compares to 20 seconds treatment $(32.5 \mathrm{mmohs} / \mathrm{cm})$. As the seed aging progress towards sever aging, the electrolyte leakage increased drastically (Fig. 3). At the no seed priming condition, the highest electrolyte leakage was observed at 96 hours of accelerated aging $(62.3 \mathrm{mmohs} / \mathrm{cm})$, while the lowest was $(24.1 \mathrm{mmohs} / \mathrm{cm})$ for the no aged seeds. It was reported that seed priming significantly reduced the electrolyte conductivity from aged soybean seeds (Tilden and West, 1985). However, our results revealed that using ultrasonic in seed priming, the amount of electrolyte leakage would be higher compared to no treated seeds. Our results are in agreement with (Wang et al., 2016), that uncover the positive relationship between the malondialdehyde activity and electrolyte leakage from the artificially aged seeds. It has been shown that the electrical conductivity test is an indirect measurement of membrane integrity condition (Vieira et al., 2002). This method was successfully applied to determine the vigor conditions of sesame seeds (Cruz et al., 2013).

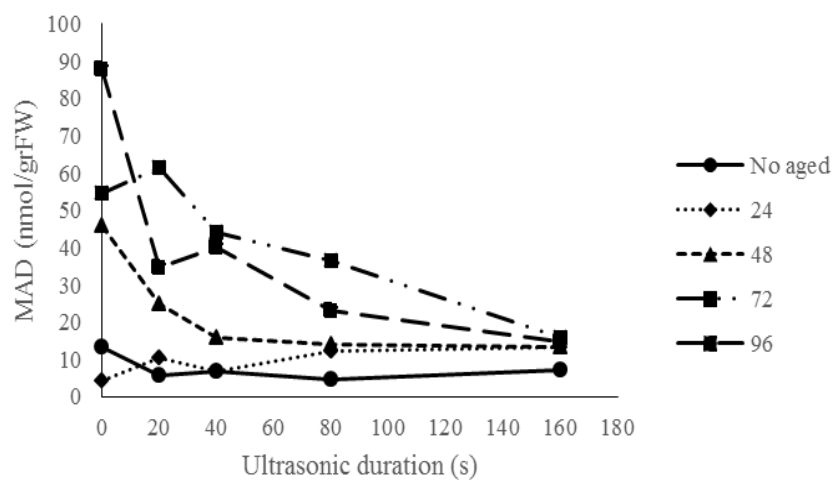

Fig. 2. Interaction effects of aging (hour) and ultrasonic assisted seed priming (seconds) on the MAD activity of Silybum marianum seeds

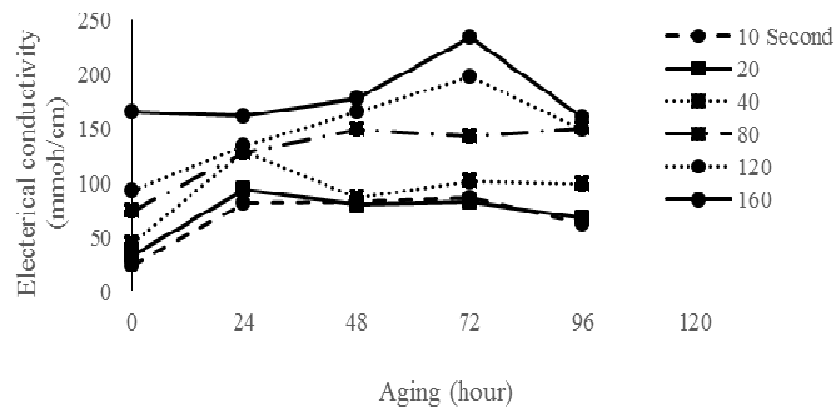

Fig.3. Interaction effects of aging and Ultrasonic assisted seed priming on the membrane integrity of Silybum marianum seeds 


\section{Fatty acid composition}

The fatty acid composition of Milk thistle seed oil is presented in Table 2. The linoleic acid was the most abundant fatty acid among and account for $70 \%$ of seed oil in no aged seeds. However, application of ultrasonic treatments alters the seed oil composition and decreased it to $60 \%$. Results were in accordance with (Nasrollahi et al., 2016; Meddeb et al., 2017) Accelerated aging was also influenced seed oil composition of Milk thistle (Table 2) and linoleic content was declined as the aging progress. Similar results was reported about reduction of linoleic and oleic acid content of wheat fatty acid composition due to accelerated aging treatment (Ouzouline $e t$ al., 2009). It has been reported that accelerated aging caused changes in ration of saturated to unsaturated fatty acids of Dalbergia sissoo Roxb. seeds (Thapliyal and Connor, 1997). It has been shown that increase of accelerated aging led to higher production of free fatty acid ad malonaldehyde activity in Maze seeds (Basavarajappa et al., 1991). Our results suggested that seed fatty acid composition of Silybum marianum is very sensitive to storage conditions.

Table 2. Effect of ultrasonic assisted seed priming durations on the fatty acid compositions of aged ( 96 hour) and no aged Silybum marianum seeds

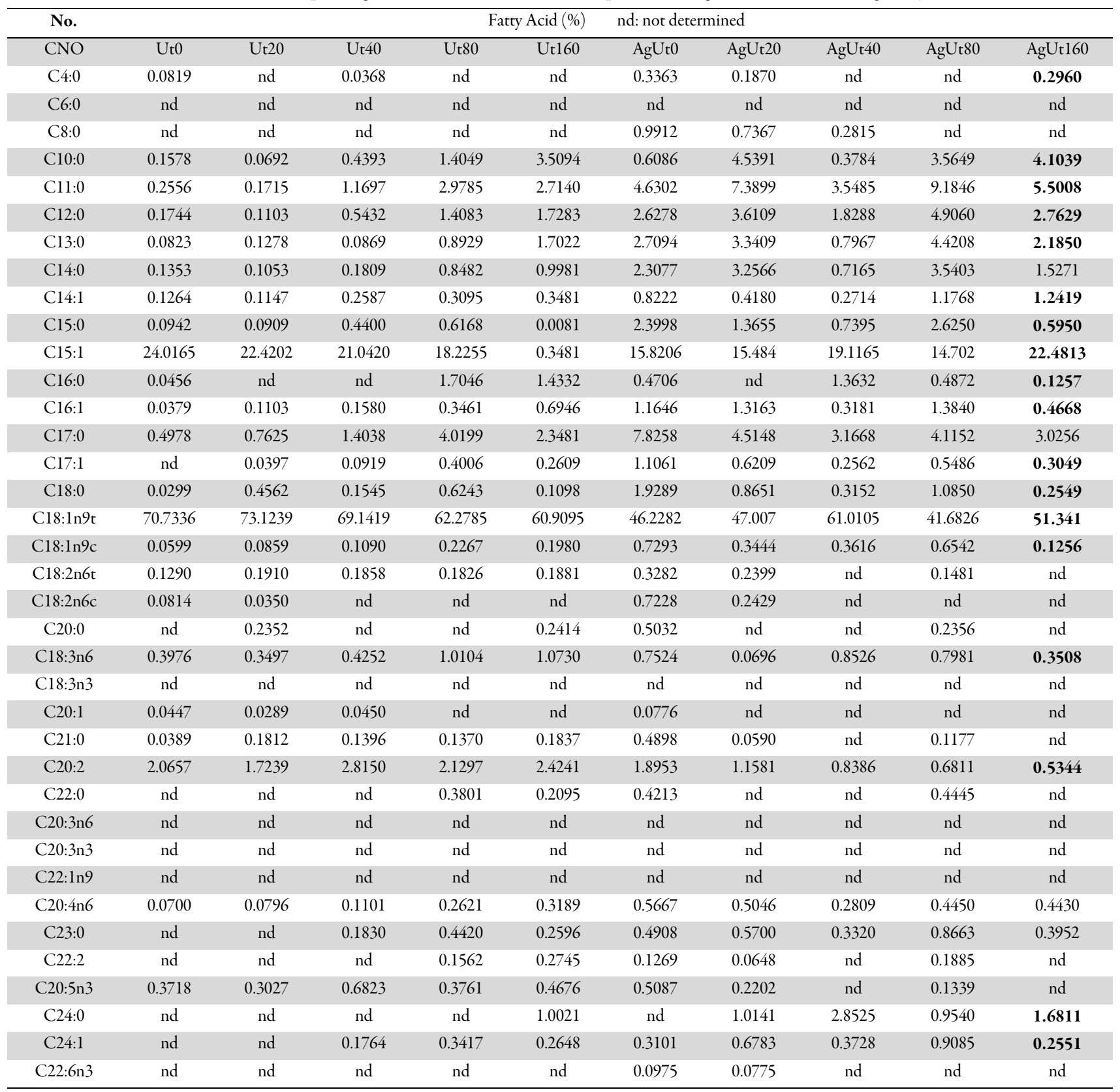




\section{Conclusions}

Ultrasonic assisted seed priming does not provide satisfactory in improvements of aging damages. However, under no aged conditions, ultrasonification enhanced seed germination and antioxidant activities. Results revealed that accelerated aging caused considerable changes to fatty acid composition of seed oil. It is therefore concluded that ultrasonic seed priming is not recommended to alleviate accelerated aging damages of milk thistle seeds.

\section{References}

Andrzejewska J, Sadowska K (2008). Effect of cultivation conditions on the variability and interrelation of yield and raw material quality in milk thistle (Silybum marianum (L.) Gaertn.). Acta Scientiarum Polonorum Agricultura 7(3).

Adzet T, Iglesias J, Martinez F (1993). Flavonolignans in the fruits of Silybum genus taxa: a chromatographic and mass spectrometric survey. Plantes Médicinales et Phytothérapie 26:117-129.

Albassam AA, Frye RF, Markowitz JS (2017). The effect of milk thistle (Silybum marianum) and its main flavonolignans on CYP2C8 enzyme activity in human liver microsomes. Chemico-Biological Interactions 271:24-29.

Andrzejewska J, Sadowska K (2008). Effect of cultivation conditions on the variability and interrelation of yield and raw material quality in milk thistle (Silybum marianum (L.) Gaertn.). Acta Scientiarum Polonorum Agricultura 7(3).

Bailly C, Benamar A, Corbineau F, Côme D (1998). Free radical scavenging as affected by accelerated ageing and subsequent priming in sunflower seeds. Physiologia Plantarum 104:646-652.

Basavarajappa BS, Shekar Shetty H, Prakash HS (1991). Membrane deterioration and other biochemical-changes, associated with accelerated aging of maize seeds. Seed Science and Technology 19:279-286.

Benamar A, Tallon C, Macherel D (2003). Membrane integrity and oxidative properties of mitochondria isolated from imbibing pea seeds after priming or accelerated ageing. Seed Science Research 13:35-45.

Çelik HT, Gürü M (2015). Extraction of oil and silybin compounds from milk thistle seeds using supercritical carbon dioxide. The Journal of Supercritical Fluids 100:105-109.

CruzSM, Nery MC, Rocha AdeS, Von PinhoÉV de R, Andrade PC de R, Dias DCF dos $S$ (2013). Vigor tests for evaluation of crambe (Crambe abyssinica Hochst) seed quality. Journal of Seed Science 35:485-494.

David F, Vickers AK (2005). Column Selection for the analysis of fatty acid methyl esters (Application for Food Analysis). Agilent Technologies:112 Available at: https://www.agilent.com/cs/library/applications/59893760EN.pdf.

Demir I, Mavi K (2008). Controlled deterioration and accelerated aging tests to estimate the relative storage potential of cucurbit seed lots. HortScience 43:15441548.

Flora K, Hahn M, Rosen H, Benner K (1998). Milk thistle (Silybum marianum) for the therapy of liver disease. The American Journal of Gastroenterology 93:139.

Gille JJP, Joenje H (1991). Biological significance of oxygen toxicity: An introduction. MembraneLipid Oxidation 3:1-32.
Goel A, Goel AK, Sheoran IS (2003). Changes in oxidative stress enzymes during artificial ageing in cotton (Gossppium hirsutum L.) seeds. Journal of Plant Physiology 160:1093-1100.

Gresta F, Avola G, Guarnaccia P (2007). Agronomic characterization of some spontaneous genotypes of milk thistle (Silybum marianum $\mathrm{L}$. Gaertn.) in Mediterranean environment. Journal of Herbs, Spices and Medicinal Plants 12:51-60.

HalsteadEH, Vicario BT (1969). Effect of ultrasonics on the germination of wild rice (Zizania aquatica). Canadian Journal of Botany 47:16381640.

Heath RL, Packer L (1968). Photoperoxidation in isolated chloroplasts: I. Kinetics and stoichiometry of fatty acid peroxidation. Archives of Biochemistry and Biophysics 125:189-198.

Henning SM, Zhang Y, Rontoyanni VG, Huang J, Lee R-P, Trang A, Nuernberger G, Heber D (2014). Variability in the antioxidant activity of dietary supplements from pomegranate, milk thistle, green tea, grape seed, goji, and acai: effects of in vitro digestion. Journal of Agricultural and Food Chemistry 62:4313-4321.

ISTA (2013). International rules for seed testing. International Seed Testing Association. Available at: https://www.seedtest.org/.

Kapoor N, Arya A, Siddiqui MA, Amir A, Kumar H (2010). Seed deterioration in chickpea (Cicer arietinum $\mathrm{L}$.) under accelerated ageing. Asian Journal of Plant Sciences 9:158-162.

Karkanis A, Bilalis D, Efthimiadou A (2011). Cultivation of milk thistle (Silybum marianum L. Gaertn.), a medicinal weed. Industrial Crops and Products 34:825-830.

Kwon T, Menzel DB, Olcott HS (1965). Reactivity of malonaldehyde with food constituents. Journal of Food Science 30:808-813.

Larson RA (1997) Naturally occurringantioxidants. CRC Press.

Levine DM, Ramsey PP, Smidt RK, Ramsey PP, Smidt RK (2001). Applied statistics for engineers and scientists: using Microsoft Excel and Minitab. Upper Saddle River, NJ: Prentice Hall

Li W-Y, Yu G, Hogan RM, Mohandas R, Frye RF, Gumpricht E, Markowitz JS (2018). Relative bioavailability of Silybin A and Silybin B from 2 multiconstituent dietary supplement formulations containing milk thistle extract: A single-dose study. Clinical Therapeutics 40:103113.

Liu J, WangQ, KaragićĐ, Liu X, CuiJ, GuiJ, Gu M, Gao W(2016). Effects of ultrasonication on increased germination and improved seedling growth of aged grass seeds of tall fescue and Russian wildrye. Scientific Reports 6:22403.

McDonald MB (1999). Seed deterioration: physiology, repair and assessment. Seed Science and Technology 27:177-237.

Meddeb W, Rezig L, Abderrabba M, Lizard G, Mejri M (2017). Tunisian milk thistle: An investigation of the chemical composition and the characterization of its cold-pressed seed oils. International Journal of MolecularSciences 18(12):2582.

Nasrollahi I, Talebi E, Nemati Z (2016). Study on Silybum marianum seed through fatty acids comparison, peroxide tests, refractive index and oil percentage. Pharmacognosy Journal 8:595-597.

Orchard TJ (1977). Estimating the parameters of plant seedling emergence. Seed Science and Technology.

Ouzouline M, Tahani N, Demandre C, El Amrani E, Benhassaine-Kesri G, 
Serghini Caid H (2009). Effects of accelerated aging upon the lipid composition of seeds from two soft wheat varieties from Morocco. Grasasy Aceites 60:367-374.

Parmoon G, Ebadi A, Jahanbakhsh S, Davari M (2013). The effect of seed priming and accelerated aging on germination and physiochemical changes in milk thistle (Silybum marianum). Notulae Scientia Biologicae 5(2):1-8.

Sauer DB (1986). Disinfection of seed surfaces with sodium hypochlorite. Phytopathology 76(7):745-749.

Scott SJ, Jones RA, Williams Wa (1984). Review of data analysis methods for seed germination. CropScience 24:1192-1199.

Sharififar A, Nazari M, Asghari HR (2015). Effect of ultrasonic waves on seed germination of Atriplex lentiformis, Cuminum cyminum, and Zygophyllum eurypterum. Journal of Applied Research on Medicinal and Aromatic Plants 2:102-104.

Souza FFJ, Spehar CR, Souza NOS, Fagioli M, Souza RTG, Borges SR (2017). Accelerated ageing test for the evaluation of quinoa seed vigour. Seed Science and Technology 45:212-221.

Stewart RR, Bewley JD (1980). Lipid peroxidation associated with accelerated aging of soybean axes. Plant Physiology 65:245-248.
Thapliyal RC, Connor KF (1997). Effects of accelerated ageing on viability, leachate exudation, and fatty acid content of Dalbergia sissoo Roxb. seeds. Seed Science and Technology (Switzerland).

Tilden RL, West SH (1985) Reversal of the effects of aging in soybean seeds. Plant Physiology 77:584586.

Vieira RD, Penariol AL, Perecin D, Panobianco M (2002). Condutividade elétrica e teor de água inicial das sementes de soja. Pesquisa Agropecuária Brasileira 37:1333-1338.

Wang Q, Yang M, Pei J, Wang L, Wu YY, Lv H (2016). Effect of moisture content on vigor of Cyathula officinalis seeds and its anti-aging mechanism analysis. Zhongguo Zhong yao za zhi= Zhongguo zhongyao zazhi= China Journal of Chinese Materia Medica 41(7):1222-1226.

Yaldagard M, MortazaviSA, Tabatabaie F (2008). Application of ultrasonic waves as a priming technique for accelerating and enhancing the germination of barley seed: Optimization of method by the Taguchi approach. Journal of the Institute of Brewing 114:1421. 